\title{
europhysics news
}

features

\section{EXTRASOLAR PLANETS}

Jupiter-like Planet Discovered

The Heliosphere and its Neighbourhood

high energy physics conference

\section{Seeking a Comprehensive Understanding}

physics and society

\section{Polish Society Celebrates its 75th Year}

INTERNATIONAL USER FACILITIES

Wroclaw's High Fields at Low Temperatures

\section{SCIENCE IN POLAND}

A Broader Backdrop

\section{europhysics notes}

Organizations; European Commission;

Sociology of Science; Research reactors;

CERN; Publications; Personalities

\section{information to eps members}

\section{A Broad Range of Activities}

EPS CONSTITUTION: Proposed Amendments

Executive Committee Decisions

1996 HPE Prize: Opening the Door to Bright Prospects

PhysDoc Index Search

Quantum Electronics Prize

High-Energy and Particle Physics Board

135

EPS Sponsored \& Organized Conferences

\section{europhysics meetings list}

\section{Conferences 1996 Schools 1996}

136

\section{European Physical Society ${ }^{\odot}$}

Europhysics News is the bulletin of the European Physical Society, published at least six times each year. Subscription price: SFR 135-- p. a.

\section{President: H. Schopper, CERN} Sec. Gen.: G. Thomas

\section{Editorial Board}

P. Bochsler, Bern University

S. Ciliberto, ENS, Lyon

M.-C. Lemaire, CE Saclay

S. Connerade, Imperial Coll., London R. Poerschke, Springer-Verlag

A.-J. Dianoux, ILL, Grenoble

H. Ferdinande, Gent University

K. Ilakovac, Zagreb University

T. Jarlborg, Geneva University

Chairman: M. Siegrist, EPFL, Lausanne Editor: P.G. Boswell

\section{Editorial and Advertising}

EPS Secretariat, P.O. Box 69

$\mathrm{CH}-1213$ Petit-Lancy 2, Geneva

Telephone: +41 (22) 7931130

Telefax: $\quad+41(22) 7931317$

E-mail: peter.boswell@cern.ch

Subscriptions and EPS Fees

SBS Geneva; Acc. No. 164.899

Swiss PO Acc.: CCP 12-19107-4

German Post Office Acc.: Postbank

Karlsruhe 1801-30-754

\section{Advertising}

Deadline for advertising orders: first week of month of publication.

Advertising is charged according to space on a sliding scale ranging from SFR 2700.- for a full page to SFR 700.- for a one-sixth page. Rates for colour and cover advertising and for series insertions on request. Special rates for EPS members and for positions vacant.

\section{Cover illustration}

A column of gas and dust is slowly eroded away by light from nearby hot stars leaving small globules of dense gas (Evaporating Gaseous Globules). The shadows of the EGGs protect the gas behind them, resulting in finger-like projections at the top of the cloud. Forming inside the EGGs are embryonic stars that abruptly stop growing when the EGGs are uncovered. Eventually, stars emerge from EGGS as the EGGs themselves succumb to photoevaporation. Radiative stripping in a different context may explain the origin of the first extrasolar planetary system to be discovered (p. 123). Photo courtesy of the Hubble Space Telescope.

\section{More Discrimination}

Satisfying readers occupies most publications no matter what the format. The Editorial Board of Europhysics News has discussed for some time the need for a readership survey. It was discouraged by the undiscriminating results of surveys carried out by similar publications showing that $25 \%$ of readers agreed with everything one did. Moreover, the context was rapidly evolving with the distribution to national society members as from last January, expansion of the Board to reflect the enlarged EPS membership, and the collaboration with Springer-Verlag that sees the company taking over the production and distribution of Europhysics News as from the next issue.

Perhaps a more stable situation, a possible move of the EPS Secretariat to Mulhouse notwithstanding (p. 133), will make a readership survey worthwhile and indeed advisable. A recent survey by the Finnish Physical Society (FPS) of 400 of its some 1000 members indicates that there is now some hope that the results would reflect greater discrimination.

Of the (representative) $25 \%$ who replied, $98 \%$ and $73 \%$ read the FPS bulletin and Europhysics News, respectively, $86 \%$ read the scholarly publication (published in collaboration with the Finnish Mathematical Society), and $25 \%$ regularly consulted the FPS WWW server for information. So the level of interest was very high and variety much appreciated. Moreover, while some items in the bulletin were read by over $70 \%$ of readers, others only interested some $20 \%$.

It would be jumping to conclusions to say that the greater appreciation of a variety of formats and content stems from the emergence of electronic publications and information sources which emphasise the value of traditional forms by offering new ones. But something has changed in reader awareness.

Tracking changing tastes via surveys seems feasible; tracking publications themselves will become more difficult. The Society has recently taken some first steps by launching under its EurophysNet umbrella a service called PhysDoc that generates a searchable index of electronic documents (p. 135). The aim is to tune the system to find and point to the location of accessible documents, and not simply references, and to extend index building beyond physics departments in European universities. Such efforts are, of course, largely voluntary, with EPS providing the indispensable continuity that is often forgotten in the rush to something new in the electronic world.

P.G. Boswell

\section{ACKNOWLEDGEMENT}

The Editorial Board and the Editor wish to take this opportunity to thank Pfirter Frères SA who have produced Europhysics News for the last 15 years for their exemplary service. The company - a family run enterprise - continually adapted its technology to meet the highest standards while reducing costs. 